Article

\title{
Measures and Steps for More Efficient Use of Buildings
}

\author{
Mattias Höjer $^{1}$ (1) and Kristina Mjörnell ${ }^{2, *}$ (it) \\ 1 Division of Strategic Sustainable Studies, Department of Sustainable Development, Environmental Science \\ and Engineering, KTH Royal Institute of Technology, 10044 Stockholm, Sweden; hojer@kth.se \\ 2 RISE Research Institutes of Sweden, Eklandagatan 86, 41261 Gothenburg, Sweden \\ * Correspondence: kristina.mjornell@ri.se; Tel.: +46-730-88-57-45
}

Received: 1 May 2018; Accepted: 8 June 2018; Published: 11 June 2018

\begin{abstract}
As urbanization continues and more people move into cities and urban areas, pressure on available land for new constructions will continue to increase. This situation constitutes an incentive to review the need for interior space and uses of existing buildings. A great deal can be gained from using existing buildings more efficiently instead of constructing new ones: Reduced resource usage during construction (investments, natural resources, and energy), operation, and maintenance; more activity per square meter of buildings creates a greater basis for public transport and other services; more intensive use of buildings creates a more vibrant city without building on virgin land. The aim of this paper is to initiate a discussion regarding how digitalization can affect the demand and supply of interior space in existing buildings and elaborate on how policy can support more resource-efficient uses of space. New activity-based resource measurements intended for use in buildings are proposed, and several principles that have the potential to decrease environmental impact through more efficient usage of space are outlined. Based on these ideas for encouraging the flexible use of building spaces that are facilitated by digitalization and the new measurement approaches, a four-step principle for construction is proposed: The first step is to reduce the demand for space, the second is to intensify usage of existing space, the third is to reconstruct and adapt existing buildings to current needs, and the fourth is to construct new buildings. Urging political, municipal, construction, and real-estate decision makers to contemplate this principle, particularly in view of the new conditions that digitalization entails, will lead to more sustainable construction and, in the long term, a sustainable built environment.
\end{abstract}

Keywords: resource use; energy use; interior space utilization; buildings; sharing; digitalization

\section{Introduction}

In 2007, more than half of the population of the world lived in cities. In 2014, this figure was $54.4 \%$ and is predicted to reach $66 \%$ in 2050 [1]. One effect of urbanization and more people moving into cities and urban areas is an increased need for land for new buildings. One method of achieving this is to expand the urban areas (urban sprawl), another is to make the city denser (densification). A third is to use the existing building stock more efficiently. The EU Directive on the Energy Performance of Buildings (EPBD) [2] requires important measures to reduce the Union's energy dependency and greenhouse gas emissions and Energy Roadmap 2050 [3] explores the challenges posed by delivering the EU's decarbonization objective while at the same time ensuring security of energy supply and competitiveness. Buildings are responsible for $40 \%$ of energy consumption and $36 \%$ of $\mathrm{CO}_{2}$ emissions in the EU, and it is predicted that $50 \%$ of the building stock that will exist in 2050 will have been built before 1975 [4]. Therefore, more renovation of existing buildings has the potential to lead to significant energy savings, potentially reducing the EU's total energy consumption by $5-6 \%$ and lowering $\mathrm{CO}_{2}$ emissions by approximately $5 \%[4]$. 
During 2016-2018, the Swedish Government has been focusing on five "Innovation Partnership Programs" [5], one of those being "Smart cities". Ever since the Program started, one of the authors to this paper who is a member of the advisory board to that program, has been leading a working group with participants from academia, industry and public administrations on how to use buildings more efficiently. This paper partly stems from that group's work.

While the European construction sector was hit particularly hard by the financial and economic crisis of 2008 and is still suffering from this, the Swedish construction sector faces challenges in relation to its capacity to construct new buildings. According to a forecast from the National Board of Housing, Building and Planning, Sweden needs 600,000 new homes to be constructed before 2025, along with other facilities that will provide services to inhabitants such as schools, daycare centers, shops and recreation facilities as the population grows [6]. Sweden has some of the highest construction costs in the EU after Norway, Denmark and Switzerland according to European Construction Costs (ECC) [7] and its new housing lies primarily in the upper end of the cost bracket, making it near-impossible for many groups to enter the housing market $[8,9]$. It is not only a matter of financing and affordability of new construction, but also of decreasing the environmental impact of construction. It is high time that options for new buildings were explored more deeply. Sweden is among the countries with the highest use of space expressed as floor area per capita, with $58 \mathrm{~m}^{2}$ /capita (16 for service and 42 for residential purposes); this follows Denmark and Cyprus, with 77 and $59 \mathrm{~m}^{2} /$ capita respectively, and is almost three times the floor area per capita in Serbia with $22 \mathrm{~m}^{2} /$ capita and Romania with $24 \mathrm{~m}^{2} /$ capita [4,10]. This is an incentive to review the need for new buildings and uses of existing buildings. A more efficient use of space means a reduced demand for building space. In practice, this could have vast implications on regional planning and ideas regarding how to develop regions in a more environmentally sustainable manner.

It is becoming increasingly important to take the environmental impact of production into consideration. In order to reduce the environmental impact of buildings, the resources used in terms of energy to extract, refine, process, transport, and fabricate a material or products must also be taken into account. In recent years, many studies have shown that so-called 'embodied energy' accounts for $45 \%$ of the total energy of a low-energy building over a lifespan of 50 years [11]. An analysis of the life-cycle energy of 60 cases from nine countries showed that operating energy represents by far the greatest energy demand for a conventional building during its life cycle, whereas low-energy buildings result in a net benefit in terms of their total life-cycle energy demand, even though there is a slight increase in the embodied energy [12]. In the future, it will likely be more a rule than an exception to consider embodied energy when designing new buildings.

Meanwhile, digitalization is changing more or less every aspect of society. Among other things, this means that the ways in which interior spaces are used are changing, and will change even more in terms of both housing, where different services make it possible to share temporary homes, and the matching of supply and demand. Digitalization is also laying the foundations for various new ways of sharing offices and office desks. Taken as a whole, much is to be gained from using spaces more efficiently and, through digitalization, new opportunities for this are appearing.

Thus, it seems there are potential environmental, social and economic benefits in using buildings more efficiently, and that digitalization can give some tools making this more feasible that previously. This paper focuses on Sweden because of the circumstances in that country described above. Even if this paper stems from Sweden, the general ideas should be relevant in all nations. It may however be more relevant for nations with a relatively high amount of building area, measured as square meter per capita. Some of the benefits of using buildings more efficiently rather than building new ones are:

(i) Resource efficiency in construction can increase.

(ii) Energy use for heating and operation can be reduced.

(iii) More people per square meter creates better support for public transport and other services.

(iv) More intensive usage of buildings creates more vibrant neighborhoods without building on virgin land. 


\subsection{Aim}

The aim of this paper is to explore a new principle for reducing the resource use of buildings, and to combine this with a structured approach to discussing how interior space can be more efficiently used. How can these two perspectives highlight new avenues for policy development and new areas of innovation? In relation to this, several issues involving how requirements on measures for energy use in buildings can be formulated to assist in the drive for decreasing greenhouse gas emissions for the building stock, and the opportunities for change that come with digitalization, are explored.

\subsection{Background}

The following subsections of this paper introduce three important principles relating to reduced use of resources, the sharing of interior space, and alternative measures for energy use in buildings. These three subsections are the foundations of the 'Results' section that they precede.

\subsubsection{Principles for Reducing Usage of Resources}

Several sectors and areas have developed principles for increasing resource efficiency. Within transport infrastructure policy, the Swedish Transport Administration has explored the 'four-step principle' $[13,14]$, which states that possible improvements to the transport system should be considered in a specific order. The first step is to consider measures that can affect the demand for transportation and choice of mode of transport. The second is to consider measures that could lead to more efficient uses of existing infrastructure. The third is to consider limited reconstructions. The fourth, which is only to be considered if the first three are not sufficient, is new and large-scale investment in the construction of road infrastructure [13]. Another example of guiding resource use through general policies is the 'waste management hierarchy', which is part of the EU waste directive (see Figure 1) [15]. The hierarchy states that, in order to reduce the negative impact of waste, five steps should be taken. Step 1 states that waste should be avoided through measures relating to product development and design. Steps $2-5$ relate to when a product has become waste and focus on ways of reusing, recycling, and, as a last resort, disposing of products.

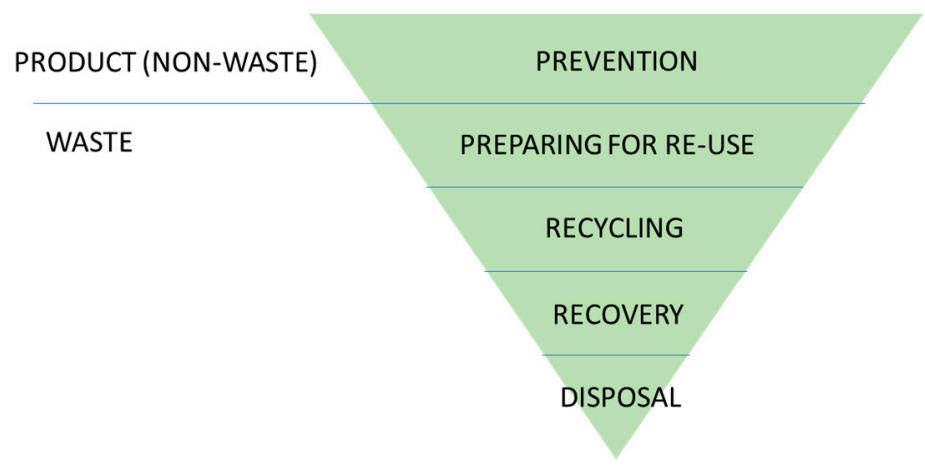

Figure 1. The 'waste management heirarchy'.

Within the area of energy use in buildings, there exist a number of strategies that resemble the 'waste management hierarchy' and the 'four-step principle' for transport. Berggren and Wall [16] identify four such strategies-'the Energy triangle', the 'Kyoto Pyramid passive energy design process ', the 'IBC Energy Design Pyramid,' and the 'passive house design principle'-to argue that reduced energy demand is the basis for such principles, positing better insulation and more efficient ventilation as possible solutions. Further measures to be taken after energy demand is reduced are use of renewable energy and clean fossil fuels insofar as possible, with smart technologies being used for both steering and heating. 


\subsubsection{Principles for the Sharing of Interior Spaces}

An increased focus on sustainability and optimized resource usage has spurred interest in sharing things and spaces, leading to a focus on access to rather than ownership of e.g., transport modes and interior spaces.

Digitalization can assist in ensuring an increasingly efficient use of space. New sharing services have been introduced in recent years (see e.g., Reference [17]), and digital tools such as Airbnb (renting a home or property), Couchsurfing (sleeping on someone's sofa), Workaround (working in someone's office), and Coffice and Hoffice (working in a café or someone's home) allow pre-existing spaces owned by others to be utilized. These tools are part of a shift in approaches to how buildings can be used.

Different types of buildings are suitable for sharing to different extents on the part of different actors and activities. This has been studied by Brinkö et al. [18], who suggest a typology that classifies the options for sharing space and facilities within buildings for optimized use of existing buildings and minimizing the need for new ones. This was based on both literature (a large number of case studies) and interviews with stakeholders and resulted in the types of sharing being sorted into four groups. The first is sharing a specific facility-e.g., a desk or a workspace-within a semi-closed community, the second is sharing several facilities in an open or semi-closed community, the third is sharing a whole building or a physical space inside one within a closed community, and the fourth is sharing facilities between users in a network of buildings or organizations within an open, semi-closed, or closed community. These were then sorted according to a scale of sharing, from small to comprehensive. The characteristics of each type of sharing were defined by asking the following questions: What is being shared? When is it being shared? Why is it being shared? Who is sharing? How is it being shared? Digital services can be used to reveal underutilized buildings and offer space in the form of housing and premises to people and businesses who are moving into cities, thereby reducing environmental impact. CABE recommends that tenants and occupiers in office developments consider intensifying the use of space over time, taking into account increased internal and external mobility in order to achieve greater efficiency [19]. It seems like there are quite some ideas regarding how use of interior space can change, but it is not evident if the final outcome will be more or less demand for space.

\subsubsection{Alternative Measures for More Efficient Energy Use in Buildings}

For too long, there has been a too narrow focus on decreasing energy use in buildings by improving the energy efficiency of the existing building stock and creating new, low-energy buildings. The European building performance regulations are expressed in terms of $\mathrm{kWh} / \mathrm{m}^{2}$ heated area per year for buildings. This measure is advantageous for buildings that are used less frequently or by fewer users. Several recent studies, however, have explored energy use per person, rather than per square meter. Johansson [20] demonstrates that, as a performance indicator, energy use per resident is more relevant than energy performance per square meter, for all investigated building types. The average floor area per resident in multi-family buildings is lower than in 1-2 family buildings, while the energy use of many multi-family buildings is higher per square meter than that of 1-2 family buildings [15].

Sekki [21] proposes measuring energy efficiency in educational buildings by introducing indicators that take into account the number of users and the times at which a building is used. A number of new measures are suggested, taking schools as examples, including: Intensity of energy usage (energy consumption per actual number of schoolchildren using the building); specific energy consumption, adjusted for occupancy (total annual energy consumption per gross floor area times the ratio of actual daily use in relation to highest possible usage hours, i.e., 24); and specific energy consumption adjusted for usage and space efficiency (total annual energy consumption per gross area times a factor that includes the number of schoolchildren, average number of hours spent in the school per average space per schoolchild, and normal working hours- $5.5 \mathrm{~h}$ for schools and $11.5 \mathrm{~h}$ for daycare centers). 


\section{Materials and Methods}

This paper is the result of several different analyses, conducted using different research methods. First, a review of a number of approaches/tools/principles that are used as guides to reduce resource use within areas such as transport and waste was performed. Based on this, a new principle for reduced energy and resource use in buildings was developed and contextualized in relation to other relevant principles.

Secondly, several alternatives to the energy-per-square-meter metric were explored and reviewed. Based on this and a number of straight-forward examples of the forms that an intensification of space use can take, a basic categorization for the use of interior space was developed.

The combination of the principle and the categorization are proposed as something that can function as a basis for discussions regarding how space can be used more efficiently, with the potential benefits mentioned in the 'Introduction' section of this paper. Moreover, they are also proposed as potential catalysts for policy development and innovation in the 'Discussion' section, where a number of barriers to and drivers for more efficient use of interior space are summarized.

\section{Results}

\subsection{The Four-Step Principle for Sustainable Use of Interior Space}

The energy strategies in the 'Background' section are slightly less general in character than the transport and waste strategies presented. The transport and waste strategies begin with the causes of the resource use - the need for transportation and products, respectively-and then consider the aspect that is to be reduced (emissions and waste, respectively).

A corresponding approach in the energy strategies would have been to reduce the demand for climate-controlled space, and then to look at measures to reduce energy use per square meter, e.g., through insulation or more efficient heating and cooling technology.

Four steps for the sustainable use of interior space were tentatively suggested at a conference in 2017 [22], based on the four-step principle for transport infrastructure [13,14]. The four steps are further elaborated on here and contextualized in the setting of the principles for resources and energy usage in buildings, although these ignore the factor of demand for interior space. It is suggested that the four-step principle for interior spaces should be applied in any situation in which a demand for more interior space is identified. In such cases, the strategy for meeting demand should be based on a consideration of the following four steps, with the first step being the least energy- and resource-demanding:

1. Reduce the demand for space. A striking example of this is the reduction of postal and banking offices due to digitalization. Space in homes can be increased by replacing books and other physical media with digital equivalents. The storage needs of other objects could also be reduced through business-based models rather than ownership, and the highly efficient secondary market with various buy-and-sell services. Within industry, the need for remote trade is affected, and showrooms could be combined with efficient distribution via hubs to reduce the need for local space.

2. Intensify the use of existing space. If the same space requirement remains, increase space usage by using the space more intensively. This applies to office space as well as housing. With pop-up stores, it can also be applied to some extent to the retail sector. Recent decades have seen an intensification in the use of school buildings in Sweden through their being opened up to non-school activities outside of ordinary school hours. In addition, guest rooms can be shared by several households. Regardless of whether this happens on a global scale or in small groups such as within a city block, digitalization will contribute to the development of new opportunities. Households sharing space such as laundry rooms, kitchens, and social rooms allow the design and construction of small and cheap modern apartments. 
3. Rebuilding can be a way of creating more useful space through the adapting of existing buildings, renovation of attics and basements into living spaces, and transformation of homes into offices or vice versa. It can also relate to creating flexible interior spaces that challenge the boundaries between housing, offices, and the retail sector. Furthermore, it is possible to create greater flexibility and, over time, adapt existing housing to changing lifestyles as the needs of households develop.

4. New construction is the last step but can be carried out in an advantageous fashion by building one or two floors onto existing buildings or parking garages, densifying the area without exploiting more virgin land at the expense of green areas. Even in new buildings, Steps 1 and 2 should be considered so that the space created can be used efficiently and is flexible in relation to future needs.

The four steps would precede the energy strategies mentioned in 1.2.1. Since they focus on the actual demand for space, whereas strategies such as the Energy triangle focus on reduced impact once the building has already been constructed.

\subsection{Categorization of the Uses of Interior Space}

The four-step principle above encourages greater co-use of space. This is a first step towards minimizing the environmental impact of buildings (used e.g., for housing, schools, office space). Rather than allowing large premises to be heated and ventilated to no avail, total energy use can be reduced by offering space in existing houses and premises.

In principle, the utilization of interior space can be increased by increasing the activities per space unit or per time unit. Various activities are suitable for different efficient uses of interior space. For some, it is easier to reduce the space per activity or service, while for others it may be more appropriate to use a large space for a more limited time. In the following, a categorization of different activities and services in terms of efficient use of space and their potential for sharing interior space is suggested. The uses of interior spaces for activities and services (with examples from housing, the retail sector, and offices) are divided into four categories:

1. Spacious interior spaces that are sparsely used: Retired couples ('empty nesters') with more than one house who spend considerable time abroad or at a summer house; retail buildings for the trading of bulky goods such as cars, furniture, etc.; offices with large rooms for each employee, irrespective of presence.

2. Dense interior spaces that are sparsely used: Homes for students, with minimal living space that is used mainly for sleeping; retail outlets for single goods with restricted opening hours; flexible office spaces with a low employee presence.

3. Spacious interior spaces that are frequently used: A widower remaining in a large old house or apartment, spending a lot of time at home; supermarkets with long opening hours; offices with large rooms for each employee and high presence.

4. Dense interior spaces that are frequently used: Homes for the elderly with minimal living space that are in use $24 \mathrm{~h}$ a day; co-operative housing with shared common rooms; service shops with long opening hours; flexible office spaces with high employee presence.

Considering these categories, using interior space more efficiently involves moving upwards and towards the right in Figure 2. Intensifying the use of interior space by densifying or extending the time of use can be achieved as follows:

Densifying use of interior space:

- Cooperative housing, sharing common areas such as a kitchen and living room, increases the number of people living in a specific space. At Tech Farm's property in Stockholm, 55 people live in $1100 \mathrm{~m}^{2}$, which is $60 \%$ below the national average in terms of people per square meter.

- Rebuilding a house into a two-family house or generational housing (kangaroo living). 
- Increasing the number of pupils in each classroom or children in each section of daycare centers.

- Open-plan offices without individual rooms.

- Several companies sharing meeting rooms, conference facilities, reception, lounge, canteen, dressing rooms, etc., within the organization or with other organizations.

- Retail outlets sharing showrooms for displaying limited collections within a small space, in an attractive location in which people can experience the products (touch, try, assess quality, colors etc.) and then order through e-shopping.

Extending the time of use:

- Gyms, shops, etc. being open 24/7.

- Shopping malls being open in the late evening or even at night during the week, which would be beneficial for those who work late or shifts and parents with small children.

- Activity-based flexible office spaces in which employees occupy a workspace only when at the office, and use different rooms depending on activities (meeting, desk work, phone calls, creative workshops).

- Activity-based schools without home classrooms.

- Sequential school use, i.e., schools used by one group of pupils for the first half of the day and by another for the second half.

- For sporting activities that require a certain space (athletics, tennis, ice hockey) and where there is no possibility to decrease the space or squeeze more people in at the same time, the time for which the space is used could be extended.

- Canteens, gymnasiums, and receptions could be shared between schools and homes for the elderly, as is practiced on the rural island of Casö, Finland.

- Churches that are used for a couple of hours a week by a small number of people could be used for other purposes during the rest of the week-as concert halls, conference centers, shelters for the homeless, and work hubs.

- Residential space is quite difficult to share, particularly over shorter time spans, although Airbnb has proven to be a successful way of sharing an apartment or house when it is not in use, as an alternative to hotels.

- Pop-up stores could be used to display goods in an attractive location for a limited time.

- Specially equipped rooms such as operating rooms, x-ray facilities, etc. could be operated 24/7, as is the case with delivery rooms (childbirth).

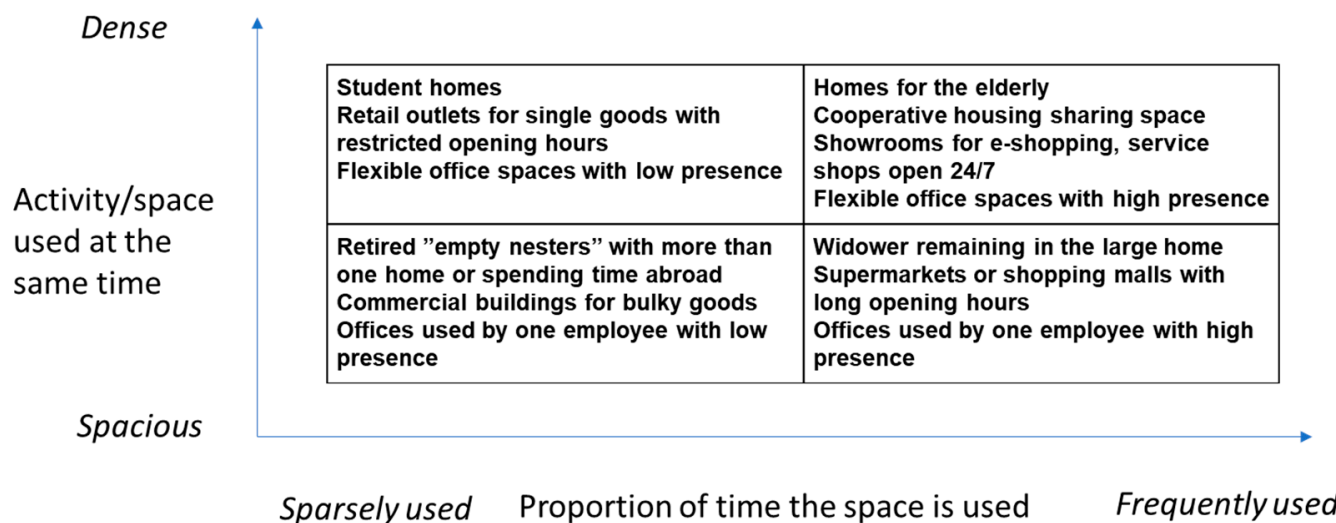

Figure 2. Categorization of use of interior space in terms of density and time of use.

It should be noted that the examples listed above function on the level of principles. The effect in practice will depend on several factors and must be thoroughly investigated. For example, the effect of 
Airbnb has generally not been found to be an intensification of housing but an inflation in the housing market, resulting in loss of housing and more accommodation for visitors [23].

\section{Discussion}

This is a conceptual paper pointing at some new approaches to energy use in buildings. We have not provided empirical findings on effects of new measures or strategies. Rather, we are bringing thoughts from other areas into the field of energy use for buildings, with the ambition to encourage further research and empirical studies based on those thoughts.

The four-step principle developed is similar to other approaches to using resources more efficiently, such as the four-step principle for transport infrastructure. However, there are also differences, the primary one being that the four steps for buildings are more strongly interconnected and so should be regarded simultaneously. By designing with the lowest need for interior space possible in mind during the planning stage, a new building can be more efficiently used. In the case of the increasing demand for housing found in growing contemporary cities, all four steps may need to be applied at the same time. This article has presented the principle as a series of steps in order to emphasize the potential of using existing buildings more efficiently.

Giving too much consideration to the average use of space per person can be risky, as it may lead to the incorrect conclusion that everyone has surplus space in their home. Evidently this is not the case, particularly in urban areas, and factors other than the positive ones must be considered when looking at space-utilization opportunities. Table 1 summarizes several drivers of and barriers to the intensified use of interior space.

Table 1. Drivers and barriers to intensified use of space in household, company, school, and retail contexts.

\begin{tabular}{|c|c|c|}
\hline & $\begin{array}{l}\text { Densifying Activities (More Activities } \\
\text { in the Same Space) }\end{array}$ & $\begin{array}{l}\text { Extending the Time of Use (Use Space for a } \\
\text { Greater Proportion of the Day, Week, Year) }\end{array}$ \\
\hline Drivers (advantages) & $\begin{array}{l}\text { Reduced environmental impact } \\
\text { Cost reduction per activity/service } \\
\text { Reduced cleaning costs for space that is } \\
\text { not used }\end{array}$ & $\begin{array}{l}\text { Reduced environmental impact } \\
\text { Cost reduction per time of use } \\
\text { Synergies between different users } \\
\text { (shared equipment) } \\
\text { Creating a vibrant atmosphere-'lively building' } \\
\text { Increased safety and security as the building is } \\
\text { in use more of the time }\end{array}$ \\
\hline Barriers (disadvantages) & $\begin{array}{l}\text { Crowded space } \\
\text { Poorer air quality } \\
\text { Need for more frequent cleaning } \\
\text { Health problems } \\
\text { Issues relating to territorial thinking, } \\
\text { security, and privacy }\end{array}$ & $\begin{array}{l}\text { Wear and tear } \\
\text { Need for frequent refurbishment, leading to } \\
\text { more material use and waste } \\
\text { Complicated logistics } \\
\text { Collisions between activities } \\
\text { Competition for the most popular time slots } \\
\text { Lack of demand during odd hours } \\
\text { and off-season } \\
\text { Need for staff } 24 \text { h a day and all year } \\
\text { Less control over availability } \\
\text { Issues relating to territorial thinking, security, } \\
\text { and privacy } \\
\text { Lack of incentives for profitability }\end{array}$ \\
\hline
\end{tabular}

During their lifetimes buildings are heated, ventilated, illuminated, cleaned, maintained, etc., entailing both costs and energy usage, which in turn have an impact on the environment. But do the regulations on energy use in buildings really encourage efficient use of energy in relation to the entire building stock? Although all new buildings are very energy efficient, any new buildings with heated spaces contribute to an increase in total energy usage. If buildings are used more frequently and by many users, the energy use will probably be slightly higher due to increased ventilation, lighting, consumption of hot water, etc. This has been observed in many multi-family housing areas built during the 1960s and 1970s, due to both poor energy performance and the fact that many people 
live in each apartment. There is undoubtedly a need to reduce energy use in these areas, but the living conditions in overcrowded apartments in socioeconomically fragile areas need to be considered. We also need to look closely at the buildings that use the most energy per person residing in each area. It may be wiser to develop policies towards resource-intensive households that have the ability to fund energy-efficiency measures to decrease their energy usage, and to encourage households that inefficiently use their living spaces to become more efficient. It is more important to reduce overall energy use than to reduce energy use per square meter.

Using indicators that represent more relevant measures of energy efficiency in buildings would be both fair and sustainable. There are, however, a number of issues that should be considered before any such measures are implemented.

Establishing the kWh-per-service or -per-activity metric, wherein a residence, workplace, school premises for a single pupil or student, daycare for a child, home for an elderly person, or place for giving birth is considered to be a service or activity, would encourage people to squeeze into smaller spaces, which means densification. The disadvantages to this are overcrowding, which can result in perceived congestion, poor air quality and health, and infections.

Establishing the kWh-per-time-used metric, wherein the built space is used for a larger proportion of the time of the day, week, or year, would encourage the use of buildings for more than one service or activity. This, however, would come with a demand on space in terms of time, which means a more intensive use of space due to the extended time of use.

The disadvantages of this are the increase in the wear and tear of the premises, as well as a lack of time for cleaning and maintenance, increased risk of collisions when changing activities, and higher incidence of double bookings and so on. The challenge would be to match different activities in terms of time, and to optimize the use of space over time. There could also be disagreements regarding interior design and furniture, limited storage possibilities, unclear division of responsibilities, and issues relating to the demands that contractual agreements place (or do not place) on co-users and co-occupants and systems of management, operation, booking, security, payment models, etc. Some premises are not attractive for use all of the time-hairdressers at night, theaters in the morning, etc.—but shopping malls, gyms, and laundry rooms could be used 24/7.

Premises for seasonal activities, such as skiing and beach resorts, could be used in other ways, such as for conferences, training courses, rehabilitation, etc. in order to extend the time of use.

As an incentive to decrease the use of interior space and hence the environmental impact of activities and utilities, this paper suggests that total GHG (greenhouse gas) emissions caused by energy use during the production of materials, transport, and operation of buildings per service provided (residence, education, work, shopping, recreation, etc.) is an accurate metric for measuring the sustainability of a building for cases in which the overall goal is to reduce GHG emissions.

Establishing a GHG-emissions-per-activity or -service metric may result in estimations of the lives of buildings that are greater than is realistic, ultimately entailing more maintenance and renovation than expected in order to continue the use of the building in the future. This would in turn increase the GHG value above the theoretical one, ultimately meaning that the initial assessment was misleading. There could also be difficulties in predicting GHG emission values for future energy production and operation of a building. Minimizing GHG emission per activity would favor the use of existing buildings as compared to new constructions.

The new dimensions and indicators that need to be developed can be based on new regulations and instruments, created for new business models for construction companies and property owners, and entail new concepts for designing housing and premises.

\section{Conclusions}

The aim of the research presented in this paper was to explore a new principle for reducing resource use in buildings, and to combine this with a structured approach to discussing how interior space can be used more efficiently. A four-step principle was developed further, involving (1) reducing 
demand for space; (2) intensifying usage of existing space; (3) rebuilding to create more useful spaces; and (4) constructing new, flexible houses. This will allow the environmental impact of the built environment and interior spaces to be decreased considerably.

A categorization of the use of interior space in terms of density and time of use has been presented. Measures for quantifying the environmental impact of buildings, expressed in terms of GHG emissions per activity rather than $\mathrm{kWh} / \mathrm{m}^{2}$, which would encourage decision makers to make more efficient use of interior space, have been presented.

By combining

- the four-step principle;

- the categorization of use of interior space;

- activity-based measures,

and suggesting approaches to matching the supply of spaces with demand that comes with the digitalization of society, we obtain an entirely new series of opportunities for policy makers (who wish to support reductions in energy and resource usage), innovators (who seek to find new areas to direct their attention towards), and business developers (who see the potential of new ways of providing space).

Researchers as well as decision makers in state functions, municipalities, and construction and real-estate companies are urged to contemplate the ingredients provided, particularly in view of the new conditions that digitalization entails. These can provide new recipes for lower resource usage, better premises, greater flexibility, and better meeting places. With this paper we have outlined a combination of ideas. Further steps include finding more data as well as exploring various ways of implementing the ideas both from a policy and from an innovation perspective.

Author Contributions: Concept, M.H. and K.M.; Methodology, M.H. and K.M.; Investigation, M.H. and K.M.; Analyses, M.H. and K.M.; Original draft preparation, M.H. and K.M.; Review and editing, M.H. and K.M.; Visualization, K.M.; Project Administration, M.H.

Funding: Costs for publishing the article was covered with the grant number 2013-1804 SIRen, the national research environment on sustainable integrated renovation, founded by the Swedish Research Council Formas.

Acknowledgments: We thank the reviewers and editors for providing constructive feedback on the manuscript.

Conflicts of Interest: The authors declare no conflicts of interest.

\section{References}

1. United Nations. World Urbanization Prospects; United Nations: New York, NY, USA, 2014; Volume 12.

2. European Parliament and Council. Directive 2010/31/EU of the European Parliament and of the Council of 19 May 2010 on the energy performance of buildings. Off. J. Eur. Union 2010, L153, 13-35.

3. European Commission. Energy Roadmap 2050; COM(2011); European Commission: Brussels, Belgium, 2012; ISBN 9789279217982.

4. BPIA. Europe's Buildings under the Microscope; Buildings Performance Institute Europe (BPIE): Bruxelles, Belgium, 2011.

5. Swedish Government Innovation Partnership Programs. Available online: https://www.government.se/ articles/2016/07/innovation-partnership-programmes--mobilising-new-ways-to-meet-societal-challenges/ (accessed on 10 June 2018).

6. Swedish Board of Housing Building and Planning. Calculation of the Need of Housing Until 2025; Swedish Board of Housing Building and Planning: Karlskrona, Sweden, 2017.

7. European Construction Costs Cost Index. Available online: http://constructioncosts.eu/cost-index/ (accessed on 10 June 2018).

8. Statistics Sweden Cost per sq. m. for newly Constructed Conventional Collectively Built One- or Two-Dwelling Buildings. Available online: http://www.scb.se/hitta-statistik/statistik-efter-amne/boende-byggande-ochbebyggelse/byggnadskostnader/priser-for-nyproducerade-bostader/pong/tabell-och-diagram/genomsnittligbyggnadskostnad-per-kvm-bostadsarea-for-gruppbyggda-smahus.-ar-riket/ (accessed on 10 June 2018). 
9. Swedish Board of Housing Building and Planning. Swedish Building Costs in an International Comparison; Swedish Board of Housing Building and Planning: Karlskrona, Sweden, 2014; ISBN 9789175630748.

10. Entranze Average Floor Area per Capita. Available online: http://www.entranze.enerdata.eu/\#/averagefloor-area-per-capita.html (accessed on 10 June 2018).

11. Thormark, C. A low energy building in a life cycle-Its embodied energy, energy need for operation and recycling potential. Build. Environ. 2002, 37, 429-435. [CrossRef]

12. Sartori, I.; Hestnes, A.G. Energy use in the life cycle of conventional and low-energy buildings: A review article. Energy Build. 2007, 39, 249-257. [CrossRef]

13. Swedish Government. Infrastruktur för Framtiden-Innovativa Lösningar för Stärkt Konkurrenskraft och Hållbar Utveckling; Swedish Government: Stockholm, Sweden, 2016.

14. Johansson, F.; Tornberg, P.; Fernström, A. A function-oriented approach to transport planning in Sweden: Limits and possibilities from a policy perspective. Transp. Policy 2018, 63, 30-38. [CrossRef]

15. European Parliament and Council. Directive 2008/98/EC of the European Parliament and of the Council of 19 November 2008 on Waste and Repealing Certain Directives. 2008. Available online: http:/ /www.reachcompliance.eu/english/legislation/docs/launchers/waste/launch-2008-98-EC.html (accessed on 8 June 2018).

16. Berggren, B.; Wall, M. Calculation of thermal bridges in (Nordic) building envelopes—Risk of performance failure due to inconsistent use of methodology. Energy Build. 2013, 65, 331-339. [CrossRef]

17. Börjesson Rivera, M. What Is a Sustainable Everyday Life?: Exploring and Assessing the Sustainability of Everyday Travel, Sharing and ICT, KTH, Strategic Sustainability Studies; KTH Royal Institute of Technology: Stockholm, Sweden, 2018.

18. Brinkoe, R.; Nielsen, S.B. The characteristics to consider in municipal shared spaces. J. Facil. Manag. 2017, 15, 335-351. [CrossRef]

19. CABE. The Impact of Office Design on Business Performance; Commission for Architecture \& the Built Environment and the British Council for Offices: London, UK, 2005.

20. Johansson, T.; Vesterlund, M.; Olofsson, T.; Dahl, J. Energy performance certificates and 3-dimensional city models as a means to reach national targets-A case study of the city of Kiruna. Energy Convers. Manag. 2016, 116, 42-57. [CrossRef]

21. Sekki, T.; Airaksinen, M.; Saari, A. Effect of energy measures on the values of energy efficiency indicators in Finnish daycare and school buildings. Energy Build. 2017, 139, 124-132. [CrossRef]

22. Höjer, M.; Ringenson, T.; Erman, M. International Conference Smart and Sustainable Planning for Cities and Regions 2015. In Digitalisation for Environmental Sustainability in a Regional Context-A Four Step Principle; EURAC Research: Bolzano, Italy, 2017; pp. 22-24.

23. Wachsmuth, D.; Chaney, D.; Kerrigan, D.; Shillolo, A.; Basalaev-Binder, R. The High Cost of Short-Term Rentals in New York City; School of Urban planning, McGill University: Montreal, QC, Canada, 2018. 